\title{
Acute Liver Failure due to Hepatitis A Virus
}

\author{
Reem Shammout $^{\mathrm{a}}$ Turki Alhassoun $^{\mathrm{b}}$ Fadi Rayya $^{\mathrm{c}}$ \\ ${ }^{a}$ Faculty of Medicine, Damascus University, Damascus, Syria; bepartment of General \\ Surgery, Faculty of Medicine, Damascus University, Damascus, Syria; 'Department of \\ General Surgery, Al Assad University Hospital, Faculty of Medicine, Damascus University, \\ Damascus, Syria
}

\section{Keywords}

Acute liver failure $\cdot$ Fulminant hepatitis $\cdot$ Hepatitis A $\cdot$ Hospital-acquired pneumonia

\begin{abstract}
Acute liver failure (ALF) is a syndrome, rather than a specific disease, with several possible causes, and viral hepatitis is a major cause. The relationship between self-limited and ALF hepatitis A is still poorly understood. A 45-year-old woman presented to our hospital with ALF diagnosis (from another hospital). She suffered from hospital-acquired pneumonia. The patient recovered within 4 weeks and returned to her normal life after 6 months of follow-up.

\section{Introduction}

According to the American Association for the Study of Liver Diseases (AASLD), acute liver failure (ALF) is defined as the presence of encephalopathy and evidence of coagulopathy via an international normalized ratio (INR) of greater than or equal to 1.5 without evidence of pre-existing cirrhosis, and persistence of symptoms is $<26$ weeks. There are many causes that can lead to ALF syndrome. It can result from an overdose of drugs, viral hepatitis, ischemia, trauma, and other causes, and each cause has a different course and outcome. The liver is able to recover after these injuries; however, predicting the clinical course is a difficult challenge. Understanding the cause of ALF is necessary to define the treatment protocol and determine the prognosis [1]. There are many classification methods that are used to grade ALF. Between 1998 and 2009, patients with hepatitis followed the diagnostic criteria for 
fulminant hepatitis that stated that ALF and late-onset hepatic failure are diagnosed as having fulminant hepatitis when hepatic encephalopathy of grade 2 at least occurs within 8 weeks of the onset of disease symptoms and is associated with a severe derangement of liver function, including a prothrombin time value of $<40 \%$ of the standardized value. The classification of acute and subacute was made according to whether encephalopathy occurred within 10 days or 11 days and later after the onset of disease symptoms, respectively [2]. Our patient presented with typical features of fulminant hepatic failure according to the definition by the AASLD, thus was classified as the acute type, where it developed encephalopathy within 7 days.

Between 2010 and 2015, patients with or without hepatitis were diagnosed as having ALF (regardless of the reason) when they manifested a prothrombin time value of $40 \%$ or less of the standardized value and/or an INR of 1.5 or more because of severe liver damage within 8 weeks of the onset of disease symptoms. The classification of having ALF with or without hepatic coma was dependent on the presence or absence of hepatic encephalopathy of grade 2 at least. Furthermore, patients with ALF with a hepatic coma were classified into 2 classes, acute and subacute, according to the period between the onset of symptoms and the manifestation of hepatic encephalopathy, so they are acute when this period is 10 days at most and subacute when this period is between 11 and 56 days $[3,4]$. This article focuses on hepatitis A virus (HAV) as a cause of ALF.ALF.

\section{Case Presentation}

A 45-year-old woman suffered from mild headache, inappetence, $39-40^{\circ} \mathrm{C}$ fever, weakness, and general fatigue. She took NSAIDS for 5 days, then presented to another hospital with the above symptoms, in addition to vomiting and light abdominal pain. Her past medical, allergic, and family history are negative. In her surgical history, there were a caesarean section and an abdomen laparoscopy. The medication history includes only NSAIDS. The social history showed that she smokes 20 packet/year and consumes alcohol occasionally.

\section{Investigations}

Abdominal ultrasound was normal, except a mild hepatic enlargement. Laboratory investigations showed that alanine transaminase $($ ALT $)=600 \mathrm{U} / \mathrm{L}$. She was diagnosed with viral hepatitis (without titration of bilirubin or hepatitis virus antibodies). Over the next 4 days, her liver enzymes continued to rise. Aspartate transaminase (AST) increased to 983 $\mathrm{U} / \mathrm{L}$ and ALT to $2173 \mathrm{U} / \mathrm{L}$. Total bilirubin increased to $10.5 \mathrm{mg} / \mathrm{dL}$ and the INR to 7.1. Whereas creatinine remained normal, the patient developed cataphora with mental confusion and then she was diagnosed with acute hepatitis next to viral hepatitis. The patient went into a coma the next day. Computed tomography of the headend abdominal ultrasound was normal, with no improvement in consciousness; thus, she was diagnosed with stage 4 hepatic encephalopathy. Based on her condition and the laboratory findings, ALF was confirmed. Then, the patient was transferred to intensive care unit, with stable vital signs. The day after, patient was intubated and showed no improvement in her neurostatus (Glasgow Coma Scale [GCS] = 3).

The next day, she was moved to our institution and re-intubated. She was treated with $\mathrm{N}$-acetylcysteine $(150 \mathrm{mg} / \mathrm{kg}$ as an initial dose, $50 \mathrm{mg} / \mathrm{kg}$ after $4 \mathrm{~h}$, and $100 \mathrm{mg} / \mathrm{kg}$ after 16 h) with lactulose, neomycin, and other supportive measures as a therapeutic regimen; her liver function was monitored carefully by laboratory investigations. Three days later, she was extubated and showed a very good improvement in her clinical status and laboratory investigations (Table 1). Table extrapolation shows the good development of the patient after her

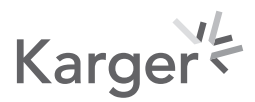




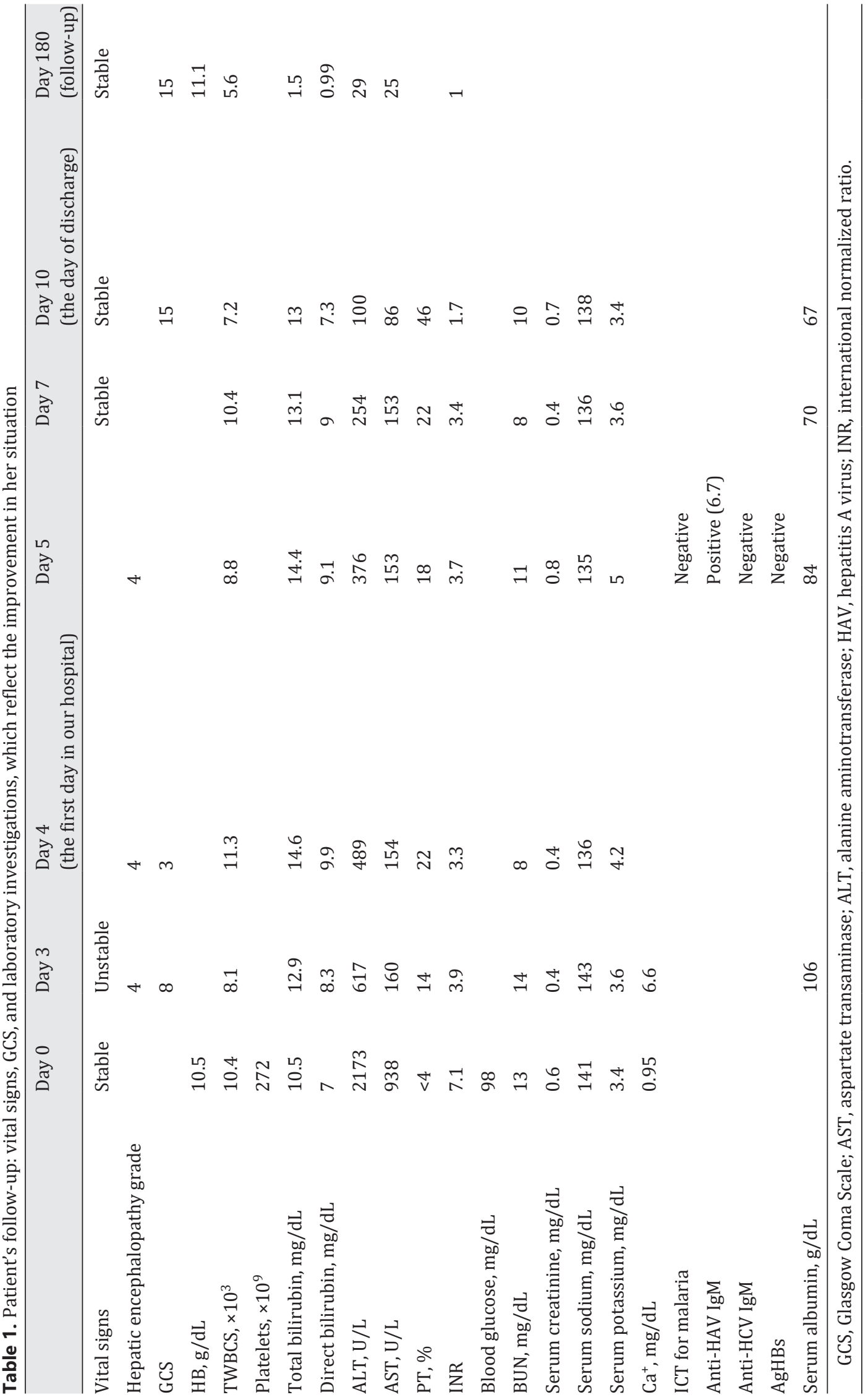


discharge from the hospital and within about 6 months of follow-up. It should be noted that abdominal ultrasound was normal during the follow-up period.

Clinical examination and laboratory findings showed that the patient developed hospitalacquired pneumonia, caused by Pseudomonas, and was treated with the suitable antibiotics. The patient was discharged from our institution on the seventh day in a good general condition.

\section{Discussion}

Throughout the years, the primary cause of ALF has changed worldwide from hepatitis $A$ and B to drug-induced liver injury being considered as the most common cause of ALF [5, 6]. In the 1960 s, hepatitis A and B counted for nearly $75 \%$ of all ALF cases. Over the last 30 years, there has been a decline in viral hepatitis in the developed world, especially hepatitis A and B, as causes of ALF [7, 8]. Currently, according to the US ALF Group Registry, druginduced liver injury (particularly acetaminophen) accounts for more than 50\% of ALF cases in this country. Indeterminate causes account for $14 \%$ of cases, with viral, autoimmune, and other rare causes accounting for the remaining cases [9]. Liver disease caused by HAV ranges from mild to severe without causing chronic liver disease. HAV is transmitted more commonly in developing countries which have poor sanitation [10]. The World Health Organization (WHO) [11] estimates about 1.4 million new cases of HAV infection yearly. Most patients with HAV recover fully, and a small proportion develops ALF [12]. HAV accounts for $3 \%$ of all cases of ALF [8]; $70 \%$ of adults infected with HAV develop symptoms and $<1 \%$ resulting in ALF [13]. In a study that was conducted during the period from January 2000 to December 2008, 92 cases of hepatitis of different etiologies were hospitalized, among which 72 (78.2\%) were caused by hepatitis A [14]. HAV prognosis: HAV-related ALF has a good prognosis, with a spontaneous resolution rate of about $70 \%$, and the remaining $30 \%$ requiring liver transplant or result in death [12]. Indications of prognosis of HAV infections include a creatinine level $>2 \mathrm{mg} / \mathrm{dL}$, an ALT $>2,600 \mathrm{U} / \mathrm{L}$, and need for intubation [15]. The presence of these indications is associated with poor prognosis, in addition to other indicators such as nonalcoholic fatty liver disease and alcoholic steatohepatitis, so such patients are more likely to develop acute on chronic liver failure from HAV [10]. Studies on the difference between patients with a benign course of HAV and those with fulminant courses have not showed clear results. There are some factors that are suggested to play a role in increasing the likelihood of developing ALF from HAV such as low viral loads and high rates of substitutions in the 50-untranslated region of the virus [16]. Early diagnosis is essential to begin early interventions in cases of virally induced ALF. Although most hepatitis A-related ALF patients recover and survive, a percentage of them die or require immediate liver transplantation [17]. As mentioned above, there is still a poor understanding of the relationship between self-limited hepatitis A cases and HAV infections, resulting in ALF (HAV ALF). Certain host-related factors including age and underlying liver disease are thought to have a role to increase the likelihood of a fulminant course $[18,19]$. In vitro studies suggest that the immunologic response is the main mechanism in the liver disease in HAV infections [20]. Also the factors associated with patient outcomes are given as follows: a related study showed that the percentage of men was higher among the deceased patients, and as for the underlying diseases, diabetes was more frequently among the deceased patients, and the study did not find any association with other underlying diseases such as hypertension and cardiovascular diseases [21].

Our patient presented with typical features of fulminant hepatic failure due to hepatitis A and did not have the risk factors that was mentioned in the cited studies, and she did not have any chronic diseases or psychiatric illnesses, as well as no risk factors for liver disease. Our patient dramatically improved within a short period and was discharged from the hospital

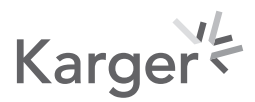


in a good condition, despite her ALF being conjugated with hospital-acquired pneumonia. This case is an example of the feasibility of $\mathrm{N}$-acetylcysteine therapy in patients with ALF of etiology other than acetaminophen poisoning. It is worth mentioning that a recent study in June of 2009 concluded that NAC improves transplant-free survival in patients with earlystage nonacetaminophen-related ALF.

\section{Acknowledgements}

The authors thank Dr. Sami Ahmad for his grateful help in treatment of the patient and Ataa Allah Marzoka for his contribution in editing of the manuscript.

\section{Statement of Ethics}

In accordance with the Declaration of Helsinki, our performed study has been approved by the Ethics Committee of the hospital. Written informed consent was obtained from the patient for publication of this case report and any accompanying images. Further information and documentation were available to the editor on request.

\section{Conflict of Interest Statement}

The authors have no ethical conflicts to disclose.

\section{Funding Sources}

No funding or grant support was received to conduct this study.

\section{Author Contributions}

The authors attest that they met the current ICMJE criteria for Authorship. Turki Alhassoun and Reem Shammout wrote the manuscript. Fadi Rayya reviewed the article. All authors read and approved the final manuscript.

\section{Availability of Data and Materials}

The datasets used during the current study are available from the corresponding author on reasonable request.

\section{References}

1 Sedhom D, D’Souza M, John E, Rustgi V. Viral hepatitis and acute liver failure: still a problem. Clin Liver Dis. 2018 May;22(2):289-300.

2 Fujiwara K, Mochida S, Matsui A, Nakayama N, Nagoshi S, Toda G, et al. Fulminant hepatitis and late onset hepatic failure in Japan. Hepatol Res. 2008;38:646-57.

3 Mochida S, Takikawa Y, Nakayama N, Oketani M, Naiki T, Yamagishi Y, et al. Diagnostic criteria of acute liver failure: a report by the Intractable HepatoBiliary Diseases Study Group of Japan. Hepatol Res. 2011;41:805-12. 
4 Sugawara K, Nakayama N, Mochida S. Acute liver failure in Japan: definition, classification, and prediction of the outcome. J Gastroenterol. 2012;47:849-61.

5 Lee W, Squires R, Nyberg S, Doo E, Hoofnagle JH. Acute liver failure: summary of a workshop. Hepatology. 2007;47:1401-15.

6 Gill R, Sterling R. Acute liver failure. J Clin Gastroenterol. 2001;33:191-8.

7 Lee W. Etiologies of acute liver failure. Curr Opin Crit Care. 2008;14:198-201.

8 Manka P, Verheyen J, Gerken G, Canbay A. Liver failure to to acute viral hepatitis (A-E). Visc Med. 2016;32: 80-5.

9 Bernal W, Wendon J. Acute liver failure. N Engl J Med. 2013;369(26):2525-34.

10 Kemmer NM, Miskovsky EP. Hepatitis A. Infect Dis Clin North Am. 2000;14(3):605.

11 World Health Organization. WHOjHepatitis.

12 Taylor RM, Davern T, Munoz S, Han S-H, McGuire B, Larson AM, et al. Fulminant hepatitis A virus infection in the United States: incidence, prognosis, and outcomes. Hepatology. 2006;44:1589-97.

13 Jacobsen KH, Wiersma ST. Hepatitis A virus seroprevalence by age and world region, 1990 and 2005. Vaccine. 1990;28:6653-7.20052010

14 Sotelo N, de los Angeles Durazo M, Gonzalez A, Dhanakotti N. Early treatment with N-acetylcysteine in children with acute liver failure secondary to hepatitis A. Ann Hepatol. 2009 Oct-Dec;8(4):353-8.

15 Ajmera V, Xia G, Vaughan G, Forbi JC, Ganova-Raeva LM, Khudyakov Y, et al. What factors determine the severity of hepatitis A-related acute liver failure? J Viral Hepat. 2011;18:e167-74.

16 Fujiwara K, Yokosuka O, Ehata T, Saisho H, Saotome N, Suzuki K, et al. Association between severity of type A hepatitis and nucleotide variations in the 50 non-translated region of hepatitis A virus RNA: strains from fulminant hepatitis have fewer nucleotide substitutions. Gut. 2002;51:82-8.

17 Schiodt FV, Davern TJ, Shakil AO, McGuire B, Samuel G, Lee WM. Viral hepatitis-related acute liver failure. Am J Gastroenterol. 2003; 98:448-53.

18 Brown GR, Persley K. Hepatitis A epidemic in the elderly. South Med J. 2002;95:826-33.

19 Vento S. Fulminant hepatitis associated with hepatitis A virus superinfection in patients with chronic hepatitis C. J Viral Hepat. 2000;7(Suppl 1):7-8.

20 Fleischer B, Fleischer S, Maier K, Wiedmann KH, Sacher M, Thaler H, et al. Clonal analysis of infiltrating T lymphocytes in liver tissue in viral hepatitis A. Immunology. 1990;69:14-9.

21 Nakao M, Nakayama N, Uchida Y, Tomiya T, Oketani M, Ido A, et al. Deteriorated outcome of recent patients with acute liver failure and late-onset hepatic failure caused by infection with hepatitis A virus: a subanalysis of patients seen between 1998 and 2015 and enrolled in nationwide surveys in Japan. Hepatol Res. 2019 Aug; 49(8):844-52. 